\title{
Preparation and characterization of single phase, biphasic and triphasic calcium phosphate whisker-like fibers by homogenous precipitation using urea
}

\author{
Zahra Mohammadi ${ }^{1}$, Abdorreza Sheikh-Mehdi Mesgar ${ }^{2}$, Fariba Rasouli-Disfani
}

\begin{abstract}
Bioceramics and Implants Laboratory, Faculty of New Sciences and Technologies, University of Tehran, Tehran 1439955941, Islamic Republic of Iran
\end{abstract}

\begin{abstract}
Whisker-like calcium phosphate fibers were prepared by a homogenous precipitation method under refluxing conditions in solutions with a $\mathrm{Ca} / \mathrm{P}$ molar ratio of 1.67 at $90^{\circ} \mathrm{C}$ and $\mathrm{pH} 3.0 \mathrm{using}$ urea as additive. The precipitates were characterized by XRD, FTIR, SEM, and FE-SEM. The ICP spectroscopy and elemental analyzer were used to determine $\mathrm{Ca} / \mathrm{P}$ ratio and carbonate content of products, respectively. The results indicate that the morphology and structural characteristics of the precipitates depend on the urea concentration and reaction time. Whisker-like biphasic monetite/hydroxyapatite (HA) fibers with a mean length of $60 \mu \mathrm{m}$ and a mean width of $1.0 \mu \mathrm{m}$ were obtained with the use of a low concentration of urea. Calcination of the biphasic calcium phosphate at $800{ }^{\circ} \mathrm{C}$ led to the formation of a triphasic mixture of HA/whitlockite ( $\beta-\mathrm{TCP})$ /calcium pyrophosphate (CPP) with a whisker-like morphology. The use of a higher concentration of urea was caused to form a mixed morphology of spherulites/whisker-like fibers consisting of octacalcium phosphate (OCP) and HA phases. When the reaction time was increased to 10 days, both the above biphasic calcium phosphates transformed to a single phase HA which its morphology and growth pattern were similar to those of a whisker, according to FE-SEM images. The HA whiskers produced by a lower amount of urea had a lower carbonate content compared to those obtained using a higher urea concentration.
\end{abstract}

Keywords: Calcium phosphate fibers, Monetite, Hydroxyapatite whiskers, Calcium pyrophosphate

${ }^{1}$ Corresponding author. Fax: +98 21 88617087; E-mail address: mohamadiz@ut.ac.ir (Z. Mohammadi)

${ }^{2}$ Corresponding author. Fax: +98 21 88617087; E-mail address: asmesgar@ut.ac.ir (A. S. Mesgar) 


\section{Introduction}

Whiskers as the single crystal short fibers have been known to be useful as effective reinforcements in improving the mechanical properties of composites. Despite the cytotoxicity potential of most available ceramic fibers, the hydroxyapatite (HA) whiskers have been found to be biocompatible with human body [1,2]. Therefore, they have been considered as a promising reinforcement for the composite biomaterials. Two general fields of applications have been introduced for the HA whiskers as mechanical reinforcement $[3,4]$ : ceramic matrix, and polymer matrix composites. The latter offers an appropriate system for developing the dental composites, bone substitutes, and tissue engineering scaffolds $[3,5,6]$. Most of the researches on biocompatible short fibers have focused on the use of HA whiskers, in particular wellcrystallized ones due to their close compositionally resemblance to the bone mineral [7-9]. Although the osteoconductivity of HA is excellent, its slow resorption in human body may limits its application in bone regeneration $[10,11]$. Thus, the use of low crystalline and/or carbonated HA, as well as, more soluble calcium phosphates such as dicalcium phosphate anhydrate (monetite; DCPA, $\mathrm{CaHPO}_{4}$ ) and octacalcium phosphate $\left(\mathrm{OCP}, \mathrm{Ca}_{8} \mathrm{H}_{2}\left(\mathrm{PO}_{4}\right)_{6} .5 \mathrm{H}_{2} \mathrm{O}\right)$, being faster than the well-crystallized HA due to their rapid resorbability, would be helpful in this field.

There are several methods to produce the HA whiskers such as chelate decomposition [9], hydrolysis of calcium phosphate precursors [12], homogenous precipitation [1], and hydrothermal homogenous precipitation [13]. The two latter methods are based on the hydrolysis of an organic additive which is commonly an amide used to control the solution $\mathrm{pH}$ and to modify the crystal growth. The use of several amides such as carbonyl diamide (urea) $[1,13,14]$, acetamide [14,15], formamide [13], and propanamide [16] as additive has been reported. It is believed that the use of those amides leading to a rapid rise in solution $\mathrm{pH}$ should be avoided due to the quick growth of HA, which promotes the formation of the aggregates [13]. Since urea hydrolysis occurs rapidly at $80{ }^{\circ} \mathrm{C}$ and its $\mathrm{pH}$ quickly rises above 9 , its use is not suggested under hydrothermal conditions [13]. On the other hand, the homogenous precipitation, being a slow kinetic reaction [1], is a relatively easy route and suitable for the mass production of whiskers and may be an appropriate method for preparing the hydroxyapatite whiskers using urea. In this method, the first formed phases are usually the precursors such as DCPA and OCP [1]. 
The hydrothermal homogenous precipitation method is usually used because of its fast reaction rate and its potential for preparing the HA whiskers of uniform morphology and high aspect ratio $[17,18]$. The effect of solution parameters such as calcium concentration, $\mathrm{pH}$, and $\mathrm{Ca} / \mathrm{P}$ ratio on the morphology and structural characteristics of HA whiskers obtained by the hydrothermal process have extensively been investigated [17]. Jokic et al have investigated the effect of urea concentration on phase composition and morphology of the products in the hydrothermal precipitation [19]. However, they could synthesis biphasic calcium phosphates of DCPA/HA with a morphology of plate or rod-like crystals rather than short fibers. Aizawa et al have studied the synthesis of apatite fibers by the homogenous precipitation method using the starting solutions of different ratios of $\mathrm{Ca} / \mathrm{P}$ at a given concentration of urea [20]. To the best of our knowledge, no study has been reported to find a minimum concentration of urea additive required for obtaining short fibers with whisker-like morphology in a given reaction time. Thus, the main objective of this work is to elucidate the effects of urea concentration and reaction time on the morphological and structural characteristics of products.

\section{Materials and Methods}

The synthesis was conducted through a homogenous precipitation route under acidic conditions by refluxing a mixture of aqueous solutions of calcium and phosphate ions with urea as an additive at $90{ }^{\circ} \mathrm{C}$ for various durations. The solutions were prepared by dissolving the analytical grade reagents $\mathrm{Ca}\left(\mathrm{NO}_{3}\right)_{2} .4 \mathrm{H}_{2} \mathrm{O}$ and $\left(\mathrm{NH}_{4}\right)_{2} \mathrm{HPO}_{4}$ in distilled water together with desired amounts of $0.5 \mathrm{M} \mathrm{HNO}_{3}$ to adjust an initial $\mathrm{pH} 3.0$. The calcium to phosphate molar ratio of the starting solutions for all specimens was 1.67. As can be seen in Table 1, four groups of precipitates were synthesized. In the first group (W1 to W4), the synthesis procedure was carried out at different amounts of urea, in order to find the minimum amount of urea required to form the whisker-like products. To produce whiskers using urea by homogenous precipitation method, the most works have used a concentration of $0.5 \mathrm{M}$ urea. Hence, in the second group, the precipitation was performed using 0.5M urea (i.e. 5.0 Urea/ $[\mathrm{Ca}](\mathrm{mM} / \mathrm{mM})$ ), but under different reaction times (W5 to W7). In the third group, the effect of reaction time (precipitate W8) and heat treatment at $800{ }^{\circ} \mathrm{C}$ for $2 \mathrm{~h}$ on the characteristics of precipitate W4 were studied. The precipitates were filtered 
using a filter paper through a Buchner funnel, washed with distilled water, treated with ethanol, and dried overnight at $90{ }^{\circ} \mathrm{C}$.

The crystalline phases of precipitates were characterized by X-ray diffraction (Philips-X'pert High Score, PAN analytical) using the $\mathrm{Cu} \mathrm{K}$-alpha with a scanning step of $0.02^{\circ}$; $2 \theta$ range of $3-$ $70^{\circ}$. The chemical functional groups were identified by Fourier transform infrared spectroscopy (FTIR, Perkin-Elmer Spectrum Two) within the wavenumbers of 4000-400 $\mathrm{cm}^{-1}$ using the $\mathrm{KBr}$ as standard. The morphology of products was evaluated by scanning electron microscopy (SEM, Serom, AIS2100, South Korea) and field-emission scanning electron microscopy (FE-SEM, Zeiss). Four SEM micrographs were used to select 50 fibers and their range of length and width were determined.

The contents of calcium and phosphorus of HA whiskers were determined using an inductively coupled plasma emission spectroscopy (ICP-AES; LIBERTY-RL, Varian). The contents of carbon in hydroxyapatite fibers were measured using an elemental analyzer (CHNSO Elemental Analyzer; Costech ECS 4010).

\section{Results}

Fig. 1 shows the SEM micrographs of some products (W1 to W6 in Table 1). The addition of urea was led to form spherulites of 30-50 $\mu \mathrm{m}$ (Fig. 1(c)), and then whisker-like fibers with a length within a range of $20-100 \mu \mathrm{m}$ and a width within a range of $0.2-2 \mu \mathrm{m}$, with no formation of aggregates (Fig. 1(d)). The minimum amount of urea required to form the whisker-like fibers was determined as $0.4 \mathrm{urea} / \mathrm{Ca}$ ratio under the conditions used in this study. The fibers were characterized as a biphasic calcium phosphate consisting of DCPA (PDF 01-070-1425) and HA (PDF 01-084-1998), in which the main crystalline phase was identified as monetite (Fig. 2). The strongest peak intensity belongs to the monetite and for (002) lattice plane, rather than for (200) as is usual for DCPA according to the reference PDF 01-070-1425. Meanwhile, the peak intensity ratio $\mathrm{I}_{002} / \mathrm{I}_{200}$ was higher than that of the reference. This indicates that the crystal growth was occurred along a preferred orientation. Fig. 3(a) shows the absorption spectrum of precipitate W4. The bands at 472, 562, 602, 867, 962 and $1085 \mathrm{~cm}^{-1}$ were attributed to the bending and stretching modes of the phosphate group [21]. The band of $632 \mathrm{~cm}^{-1}$ represents the existence of $\mathrm{OH}^{-}$group. The presence of $\mathrm{CO}_{3}{ }^{2-}$ group can be distinguished by the bands of 1107 
and $1457 \mathrm{~cm}^{-1}$ [21]. It is believed that these bands would be observed when the carbonate incorporated into the structure of HA [13]. The band at $1637 \mathrm{~cm}^{-1}$ may be assigned to the bending mode of water associated with HA and/or presence of DCPA [18].

In the second group of products (W5 to W7, Table 1), a significant amount of urea was used. The XRD patterns show the formation of OCP (PDF 00-026-1056) and HA (PDF 00-024-0033) which were finally transformed to a single phase of hydroxyapatite with time such that the intensity of OCP was decreased with time and disappeared after 10 days (Fig. 4). Fig. 1 (e) and (f) shows the formation of a mixture of spherulites (10-25 $\mu \mathrm{m}$ diameter) and short fibers. The fibers typically had the length within a range of 10-100 $\mu \mathrm{m}$ and width within a range of 0.2-2 $\mu \mathrm{m}$. The mixed morphology was transformed to uniform whisker-like fibers with increasing the time to 10 days (Fig. 5(a)). The XRD pattern of W7 shows a single phase of HA with the strongest peak intensity for (300) plane instead of (211) plane (Fig. 4(c)). The peak intensity ratio $\mathrm{I}_{300} / \mathrm{I}_{002}$ was higher than that of the reference (PDF 00-073-1731) which means the crystal growth has been elongated along the c-axis [17]. The FTIR results also confirmed the formation of HA (Fig. 6(b)). No characteristic peaks of OCP at 865 and $910 \mathrm{~cm}^{-1}$ were observed [15,21]. The absorption bands at 473, 561, 601 and $1028 \mathrm{~cm}^{-1}$ correspond to the phosphate group, as well as, the bands at 960 and $2396 \mathrm{~cm}^{-1}$ assigned as the $\mathrm{HPO}_{4}{ }^{2-}$ group [21]. The four peaks at the wavenumbers of $872,1106,1453 \mathrm{~cm}^{-1}$ and $1550 \mathrm{~cm}^{-1}$ were attributed to the $\mathrm{CO}_{3}{ }^{2-}$ group. The latter wavenumber indicated the formation of A-type carbonated apatite [21].

In the third group of products, the effect of long duration of synthesis (10 days) and the heat treatment at $800{ }^{\circ} \mathrm{C}$ on characteristics of precipitate $\mathrm{W} 4$ was evaluated. Figures 7 and 8 show the XRD pattern and $\mathrm{FE}-\mathrm{SEM}$ image for the heat-treated $\mathrm{W} 4$ at $800^{\circ} \mathrm{C}$ for $2 \mathrm{~h}$, respectively. The heat treatment was caused to transform the precipitate W4 into a triphasic product consisting of HA $\left(\mathrm{Ca}_{10}\left(\mathrm{PO}_{4}\right)_{6}(\mathrm{OH})_{2}, \mathrm{PDF}\right.$ 01-086-0740), whitlockite $\left(\beta-\mathrm{Ca}_{3}\left(\mathrm{PO}_{4}\right)_{2}\right.$, PDF 00-006-0426), and calcium pyrophosphate $\left(\mathrm{Ca}_{2} \mathrm{P}_{2} \mathrm{O}_{7}, \mathrm{PDF}\right.$ 01-071-2123). The triphasic product was also confirmed by FTIR analysis (Fig. 3(b)). The bands at 724 and $1209 \mathrm{~cm}^{-1}$ were assigned as $\mathrm{P}_{2} \mathrm{O}_{7}^{-4}$ [22-24]. Two absorption bands at 945 and $973 \mathrm{~cm}^{-1}$ correspond to the formation of whitlockite [21]. The bands of phosphate and hydroxyl groups were also observed. The band of carbonate seems to be disappeared for heat-treated W4 fibers. The whisker-like fibers retained their shape and size after heat treatment at $800{ }^{\circ} \mathrm{C}$ for $2 \mathrm{~h}$ (Fig. 8). Fig. 5 (c and d) shows the morphology of the 
precipitate W8. The whiskers had a mean length of $35 \mu \mathrm{m}$ and a mean width of $1 \mu \mathrm{m}$. No significant change in morphology was observed for W8 compared to W4. The absorption spectrum of precipitate W8 represented the bands of phosphate group (472, 562, 602, 962, 1028

and $1088 \mathrm{~cm}^{-1}$ ) and hydroxyl group (632 and $3570 \mathrm{~cm}^{-1}$ ) [21]. The bands at 872 and $2397 \mathrm{~cm}^{-1}$ correspond to $\mathrm{HPO}_{4}{ }^{2-}$ group [21]. No significant peaks could be found for the characteristic bands of $\mathrm{CO}_{3}{ }^{2-}$ group. Fig. 9 shows that the XRD pattern of precipitate W8 matches well with the synthetic HA pattern (PDF 01-073-0294). The intensity of (300) plane is also higher than that of the reference. Moreover, the crystal growth along a preferred orientation is occurred as a result of a higher intensity ratio of $\mathrm{I}_{300} / \mathrm{I}_{002}$ compared to the reference.

Table 2 compares the characteristics of the two types of hydroxyapatite whiskers produced in this study (W7 and W8). As expected, the elemental analysis results confirm the lower amount of carbonate in W8 compared to $\mathrm{W} 7$. The $\mathrm{Ca} / \mathrm{P}$ molar ratio of these two whiskers shows that the products were calcium-deficient hydroxyapatite. The determined intensity ratios revealed a preferred crystal growth. The growth pattern of whiskers W7 and W8 can be observed in Fig. 5 (b) and (d), respectively. The produced whiskers using a lower urea concentration (W8) had a lower carbonate content than the one produced with a higher urea amount (W7).

\section{Discussion}

In the present study, biphasic monetite/HA short fibers were prepared by an easy route of homogenous precipitation using a low amount of urea. An increase in reaction time was caused to form single phase HA whiskers. The slow reaction rate of homogenous precipitation method may lead to maintain the whisker-like morphology of biphasic monetite/HA short fibers when they exposed to long reaction durations. It should be noted that the monetite bioceramics have recently used as resorbable bone grafts due to their rapid in vivo resorbability [25]. Therefore, monetite-containing short fibers prepared in the present work would be helpful for developing composites with biodegradable reinforcements.

Calcination of nonstoichiometric hydroxyapatite at high temperatures (approximately below $1200^{\circ} \mathrm{C}$ ) usually lead to the formation of biphasic calcium phosphates of HA and $\beta$-tricalcium phosphate $(\beta-\mathrm{TCP})$ as a result of calcium deficiency of hydroxyapatite constitution. The 
biphasic short fibers produced in this study (precipitate W4) were transformed to a triphasic calcium phosphate of $\mathrm{HA} / \beta-\mathrm{TCP} / \mathrm{CPP}$ after heat treatment at $800{ }^{\circ} \mathrm{C} / 2 \mathrm{~h}$. It has been reported that DCPA is transformed to calcium pyrophosphate (CPP, $\left.\mathrm{Ca}_{2} \mathrm{P}_{2} \mathrm{O}_{7}\right)$ above $440{ }^{\circ} \mathrm{C}$ [27]. The $\beta-\mathrm{Ca}_{2} \mathrm{P}_{2} \mathrm{O}_{7}$ phase was observed above $800{ }^{\circ} \mathrm{C}$ [26]. The triphasic calcium phosphates may be formed according to the following reactions [14,26]:

$2 \mathrm{CaHPO}_{4} \rightarrow \mathrm{Ca}_{2} \mathrm{P}_{2} \mathrm{O}_{7}+\mathrm{H}_{2} \mathrm{O}$

$\mathrm{Ca}_{10-\mathrm{X}}\left(\mathrm{HPO}_{4}\right)_{\mathrm{x}}\left(\mathrm{PO}_{4}\right)_{6-\mathrm{x}}(\mathrm{OH})_{2} \rightarrow \mathrm{Ca}_{10-\mathrm{X}}\left(\mathrm{P}_{2} \mathrm{O}_{7}\right)_{\mathrm{x}}\left(\mathrm{PO}_{4}\right)_{6-2 \mathrm{x}}(\mathrm{OH})_{2} \rightarrow$

$\rightarrow 3 \mathrm{x} \beta-\mathrm{Ca}_{3}\left(\mathrm{PO}_{4}\right)_{2}+(1-\mathrm{x}) \mathrm{Ca}_{10}\left(\mathrm{PO}_{4}\right)_{6}(\mathrm{OH})_{2}+\mathrm{xH}_{2} \mathrm{O}$

Calcium pyrophosphate (CPP) is a biocompatible calcium phosphate with superior resorbability. The sintered granules of CPP have potential applications in orthopedics [27]. The CPP has been used as a sintering aid for $\beta$-TCP bioceramics [28], as well as, the reinforcement for biopolymer composites [29]. This means that triphasic HA/ $\beta$-TCP/CPP short fibers may be introduced as a biocompatible and resorbable reinforcement in composite scaffolds with a rate of resorption faster than that of HA for bone tissue engineering.

In an attempt to elucidate the effects of increasing urea concentration on morphology and structural characteristics of the products, the precipitates of W5 to W7 were prepared. The formation of mixed morphology of micro-spherulites/whisker-like fibers could be a remarkable result. Some in vitro and in vivo studies have shown that calcium phosphate microparticles interestingly represent a stimulatory behavior [30,31]. It has been reported that the ectopically implanted biphasic calcium phosphate microparticles promote the bone tissue formation through an inflammatory response which plays an important role in osteogenesis [32]. In vitro tests using the macrophages and osteoblast cells have revealed the both negative and positive effects of microparticles on osteogenesis [30]. An in vivo study showed that the rate of new bone formation around the granules consisting of the highly elongated OCP crystals was much lower than that of the granules consisting of OCP crystals up to 14 days after implantation in a mouse critical-sized calvaria defect [32]. It is believed that the OCP seems to be performing better than other calcium phosphates in vivo [33]. The aforementioned issues discern that the mixed morphology of spherulites and fibers consisting of OCP/HA mixtures may play a dual role of mechanical 
reinforcing and osteogenesis promotion. It has been recently reported that the use of a mixed morphology of spherulites and whiskers can play an important role in mechanical reinforcing of the gelatin scaffolds [34].

In this study, calcium phosphate short fibers with different constitutions and structures were prepared. These products can be considered as a promising candidate to develop the reinforced biocomposite scaffolds for bone tissue engineering.

\section{Conclusions}

Whisker-like DCPA/HA biphasic calcium phosphate fibers with the length and width within a range of 20-100 $\mu \mathrm{m}$ and 0.2-2 $\mu \mathrm{m}$, respectively, were prepared by homogenous precipitation method under refluxing conditions using a low concentration of urea. Calcination of the fibers at $800{ }^{\circ} \mathrm{C}$ led to the formation of a triphasic calcium phosphate of $\mathrm{HA} / \beta-\mathrm{TCP} / \mathrm{CPP}$ with the whisker-like morphology. A significant increase in reaction time gives rise to the transformation of the biphasic fibers into a single phase of HA with a whisker-like microstructure. With the use of a higher concentration of urea, a mixed morphology of spherulites/whisker-like fibers with OCP/HA constitutions was produced which could transform to a single phase of carbonated HA by increasing the time of precipitation.

\section{Acknowledgments}

This study was partially supported by Iran National Science Foundation (INSF) (Grant no. 92023754). We have to express our appreciation to the Professor Ali Karimi Taheri at Sharif University of Technology for his modifications and comments on the manuscript. 


\section{References}

[1] H. Zhang, Y. Wang,Y. Yan, S. Li, Precipitation of biocompatible hydroxyapatite whiskers from moderately acid solution, Ceramics international 29 (4) (2003) 413-418.

[2] S. Jalota, S.B. Bhaduri, A.C. Tas, In vitro testing of calcium phosphate (HA, TCP, and biphasic HA-TCP) whiskers, Journal of Biomedical Materials Research Part A 78(3) (2006) 481-490.

[3] R.K. Roeder, G.L. Converse, R.J. Kane, W. Yue, Hydroxyapatite-reinforced polymer biocomposites for synthetic bone substitutes, Jom 60(3) (2008) 38-45.

[4] S. Bose, A. Banerjee, S. Dasgupta, A. Bandyopadhyay, Synthesis, Processing, Mechanical, and Biological Property Characterization of Hydroxyapatite WhiskerReinforced Hydroxyapatite Composites, Journal of the American Ceramic Society 92 (2) (2009) 323-330.

[5] H. Zhang, B.W. Darvell, Mechanical properties of hydroxyapatite whisker-reinforced bisGMA-based resin composites, Dental materials 28(8) (2012) 824-830.

[6] H. Wu, D. Pang, C. Ma, Q.Li, C. Xiong, Composites of Hydroxyapatite Whiskers/poly (L-lactide-co-glycolide) with High Tensile Plasticity, Journal of Macromolecular Science, Part B 51(6) (2012) 1242-1255.

[7] W. L.Suchanek, M.Yoshimura, Preparation of fibrous, porous hydroxyapatite ceramics from hydroxyapatite whiskers, Journal of the American Ceramic Society 81(3) (1998) 765-767.

[8] S.Y. Yoon, Y.M. Park, S.S. Park, R. Stevens, H.C. Park, Synthesis of hydroxyapatite whiskers by hydrolysis of $\alpha$-tricalcium phosphate using microwave heating, Materials chemistry and physics 91(1) (2005) 48-53.

[9] R.K. Roeder, G.L. Converse, H. Leng, W.Yue, Kinetic effects on hydroxyapatite whiskers synthesized by the chelate decomposition method, Journal of the American Ceramic Society 89 (7) (2006) 2096-2104.

[10] M. Bohner, Calcium orthophosphates in medicine: from ceramics to calcium phosphate cements, Injury 31 (2000) D37-D47.

[11] M. Bohner, U. Gbureck, J.E. Barralet, Technological issues for the development of more efficient calcium phosphate bone cements: a critical assessment, Biomaterials 26 (2005) 6423-6429.

[12] A.C. Tas, Formation of calcium phosphate whiskers in hydrogen peroxide (H2O2) solutions at 90 C, Journal of the American Ceramic Society 90 (8) (2007) 23582362.

[13] H. Zhang, B.W. Darvell, Constitution and morphology of hydroxyapatite whiskers prepared using amine additives, Journal of the European Ceramic Society 30 (10) (2010) 2041-2048.

[14] H. Zhang, M. Zhang, Phase and thermal stability of hydroxyapatite whiskers precipitated using amine additives, Ceramics International 37(1) (2011) 279-286.

[15] H. Zhang, B.W. Darvell, Formation of hydroxyapatite whiskers by hydrothermal homogeneous precipitation using acetamide, Journal of the American Ceramic Society 94 (7) (2011) 2007-2013.

[16] L. Hao, H. Yang, N. Zhao, C. Du, Y. Wang, Controlled growth of hydroxyapatite fibers precipitated by propionamide through hydrothermal synthesis, Powder Technology 253 (2014) 172-177. 
[17] H. Zhang, M. Zhang, Morphology and structural characteristics of hydroxyapatite whiskers: effect of the initial $\mathrm{Ca}$ concentration, $\mathrm{Ca} / \mathrm{P}$ ratio and $\mathrm{pH}$, Acta biomaterialia 7(7) (2011) 2960-2968.

[18] I. S. Neira, F. Guitián, T. Taniguchi, T. Watanabe, M.Yoshimura, Hydrothermal synthesis of hydroxyapatite whiskers with sharp faceted hexagonal morphology, Journal of Materials Science 43(7) (2008) 2171-2178.

[19] B. Jokić, M. Mitrić, V. Radmilović, S. Drmanić, R. Petrović, D. Janaćković, Synthesis and characterization of monetite and hydroxyapatite whiskers obtained by a hydrothermal method, Ceramics International 37(1) (2011)167-173.

[20] M. Aizawa, H.Ueno, K.Itatani, I. Okada,Syntheses of calcium-deficient apatite fibers by a homogeneous precipitation method and their characterizations, Journal of the European Ceramic Society 26(4) (2006) 501-507.

[21] S. Koutsopoulos, Synthesis and characterization of hydroxyapatite crystals: a review study on the analytical methods, Journal of biomedical materials research 62(4) (2002) 600-612.

[22] B. Nasiri-Tabrizi, A. Fahami, Crystallization behavior of nanostructured amorphous tricalcium phosphate under thermal treatment, Materials Letters 106 (2013) 396-400.

[23] S. Kannan, F. Goetz-Neunhoeffer, J. Neubauer, S. Pina, P.M.C. Torres, J.M.F. Ferreira, Synthesis and structural characterization of strontium-and magnesium-cosubstituted $\beta$-tricalcium phosphate, Acta biomaterialia 6(2) (2010) 571-576.

[24] M. Descamps, J.C. Hornez, A. Leriche, Effects of powder stoichiometry on the sintering of $\beta$-tricalcium phosphate, Journal of the European Ceramic Society 27(6) (2007) 2401-2406.

[25] J. Torres, I. Tamimi, J. Cabrejos-Azama, I. Tresguerres, M. Alkhraisat, , E. López-Cabarcos, F. Tamimi, Monetite granules versus particulate autologous bone in bone regeneration, Annals of Anatomy 200 (2015) 126-133.

[26] A.C. Tas, S.B. Bhaduri, Chemical processing of $\mathrm{CaHPO}_{4} \cdot 2 \mathrm{H}_{2} \mathrm{O}$, Journal of the American Ceramic Society 87(12) (2004) 2195-2200.

[27] J.S. Sun, Y. H. Tsuang, F.H. Lin, L.T. Chen, Y.S. Hang, H.C. Liu, The application potential of sintered $\beta$-dicalcium pyrophosphate in total joint arthroplasty, The Journal of arthroplasty 18(3) (2003) 352-360.

[28] H.S. Ryu, H.J. Youn, K.S. Hong, B.S. Chang, C.K. Lee, S.S Chung, An improvement in sintering property of $\beta$-tricalcium phosphate by addition of calcium pyrophosphate, Biomaterials23(3) (2002) 909-914.

[29] A.M. El Kady, K.R. Mohamed, G.T. El-Bassyouni, Fabrication, characterization and bioactivity evaluation of calcium pyrophosphate/polymeric biocomposites, Ceramics International 35(7) (2009) 2933-2942.

[30] B.H. Fellah, B. Delorme, J. Sohier, D. Magne, P. Hardouin, P. Layrolle, Macrophage and osteoblast responses to biphasic calcium phosphate microparticles, Journal of Biomedical Materials Research Part A 93(4) (2010) 1588-1595.

[31] B.H. Fellah, N. Josselin, D. Chappard, P. Weiss, P. Layrolle, Inflammatory reaction in rats muscle after implantation of biphasic calcium phosphate micro particles, Journal of Materials Science: Materials in Medicine 18(2) (2007) 287-294. 
[32] Y. Honda, T. Anada, S. Kamakura, S. Morimoto, T. Kuriyagawa, O. Suzuki, The effect of microstructure of octacalcium phosphate on the bone regenerative property, Tissue Eng A 15 (2009) 1965-73.

[33] O. Suzuki, Octacalcium phosphate: osteoconductivity and crystal chemistry, Acta biomaterialia, 6(9) (2010) 3379-3387.

[34] M. Nouri-Felekori, A.S.M. Mesgar, Z. Mohammadi, Development of composite scaffolds in the system of gelatin- calcium phosphate whiskers/fibrous spherulites for bone tissue engineering, Ceramics International 41(4) (2015) 6013-6019. 

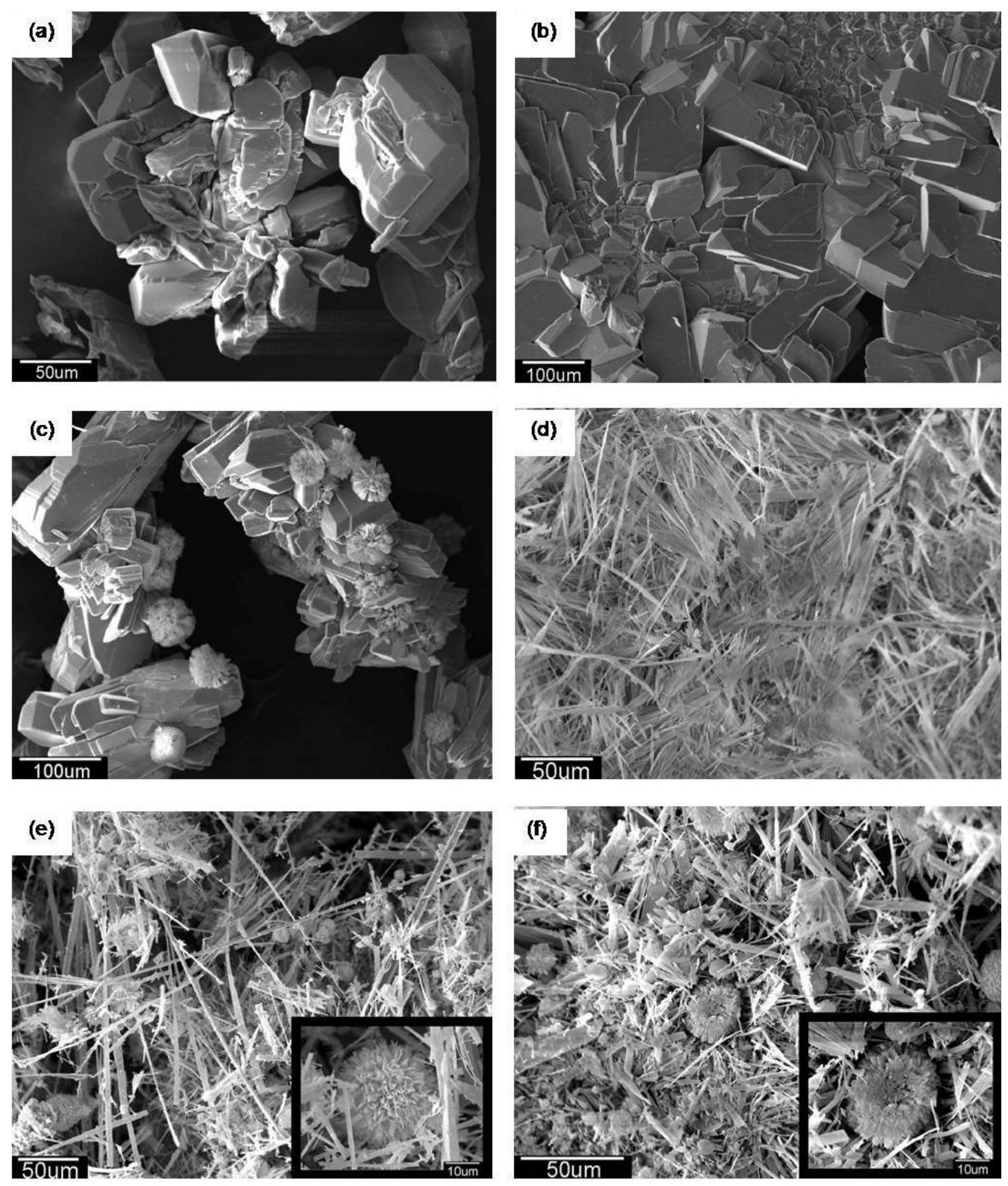

Fig. 1. SEM micrographs of products obtained at different urea contents and times (a) W1, (b) W2, (c) W3, (d) W4, (e) W5, and (f) W6. 


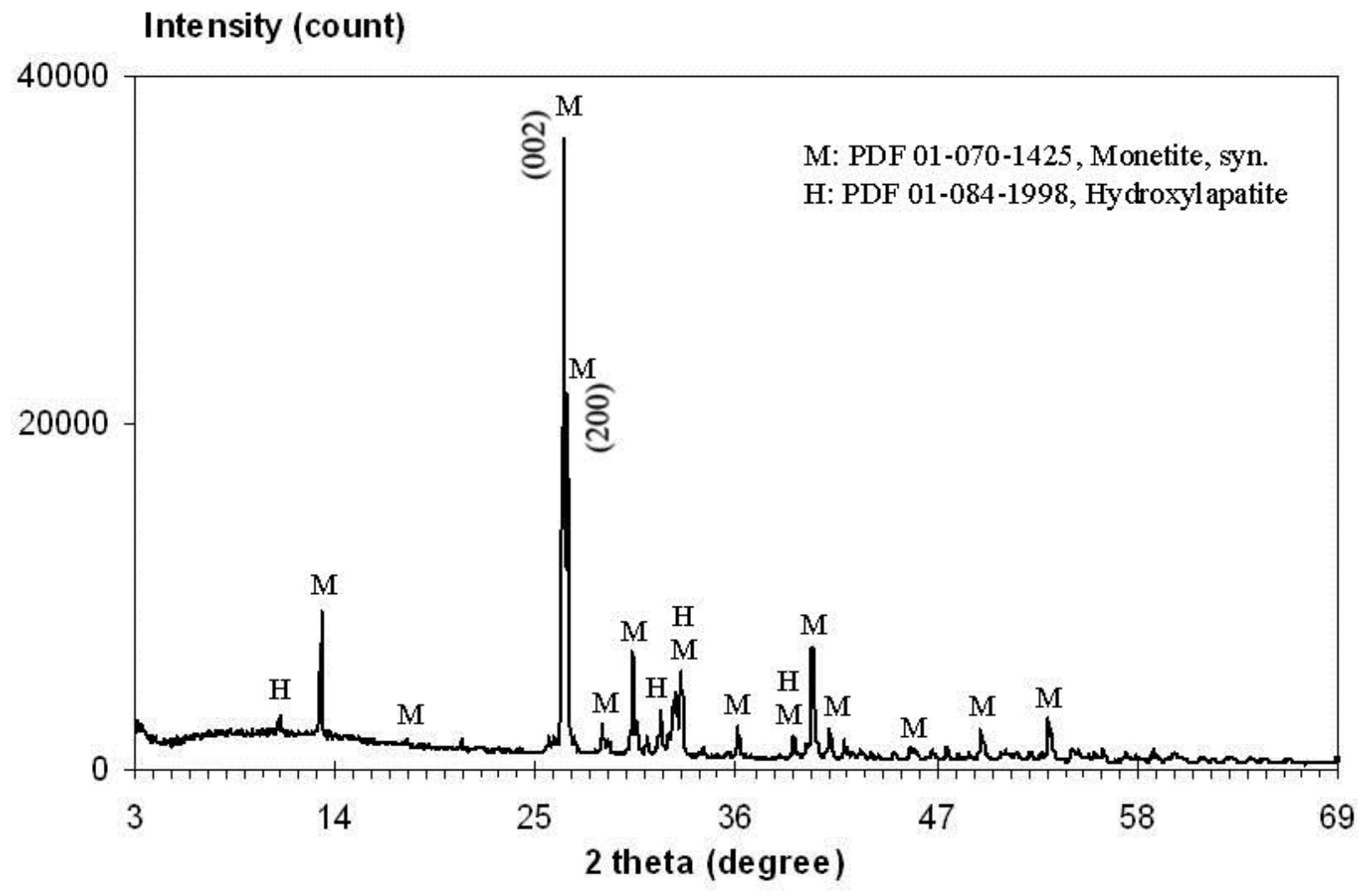

Fig. 2. XRD pattern of precipitate $\mathrm{W} 4$ obtained at 0.4 urea/Ca ratio $(\mathrm{mM} / \mathrm{mM})$ for 3 days. 


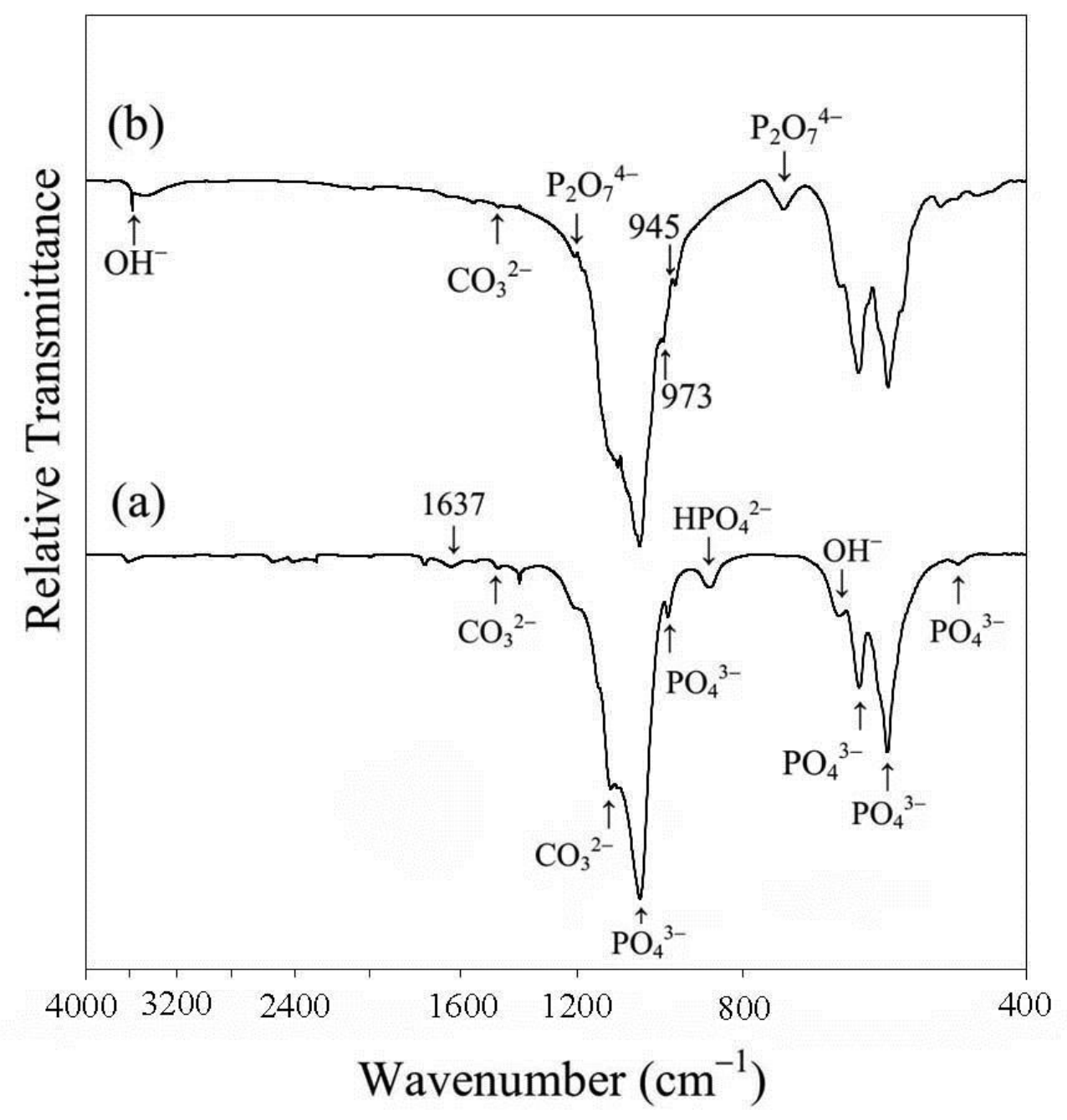

Fig. 3. FTIR spectra of W4 (a), and after heat treatment at $800{ }^{\circ} \mathrm{C}$ for $2 \mathrm{~h}(\mathrm{~b})$. 


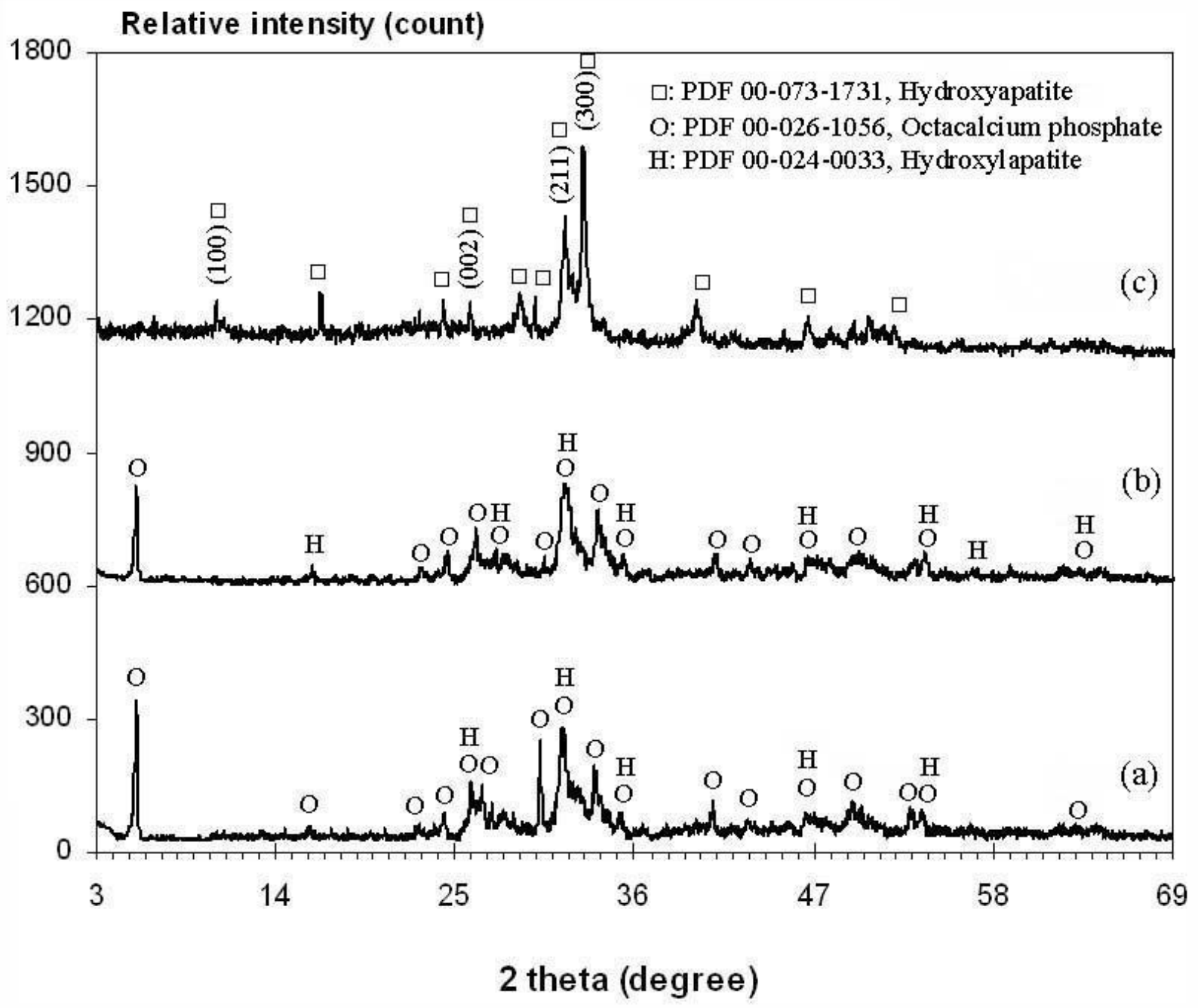

Fig. 4. XRD patterns of products obtained using a solution with 5.0 urea/[Ca] ratio at different times, (a) W5, (b) W6, and (c) W7 

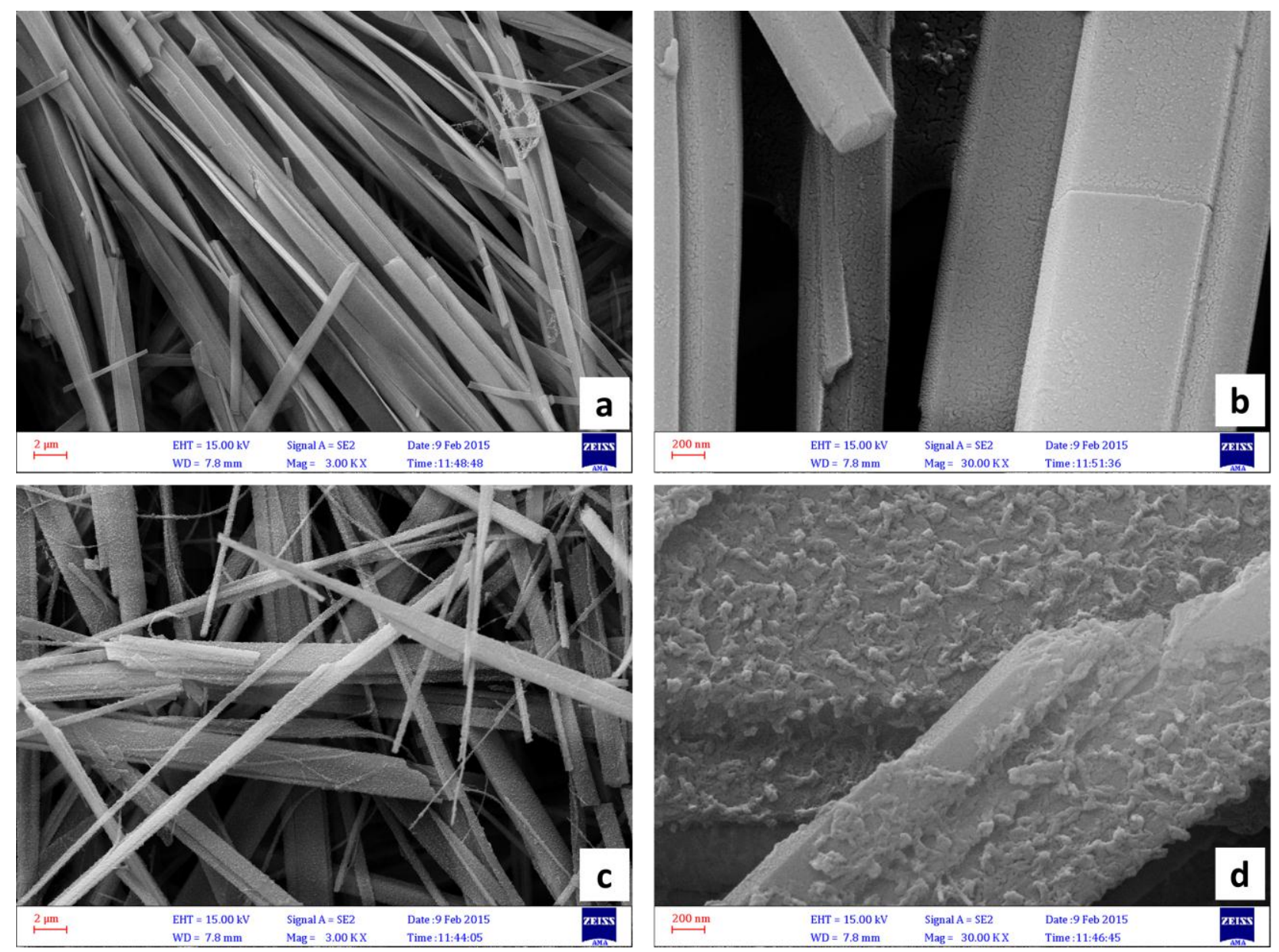

Fig. 5. Morphology and growth pattern of whiskers W7 (a, b), and W8 (c, d) at different magnifications by FE-SEM. 


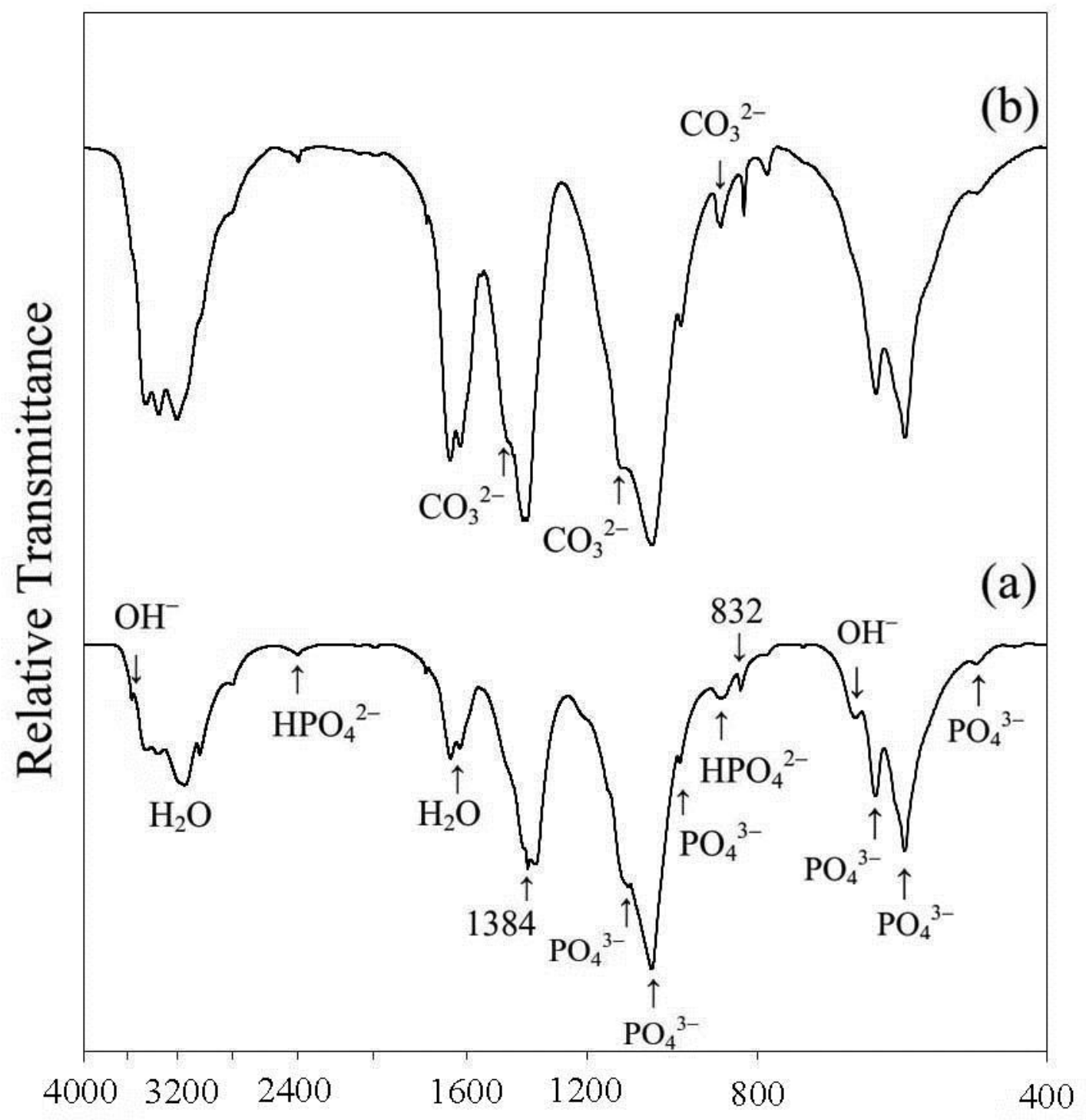

Fig. 6. FTIR spectra of whiskers (a) W8, and (b) W7. 


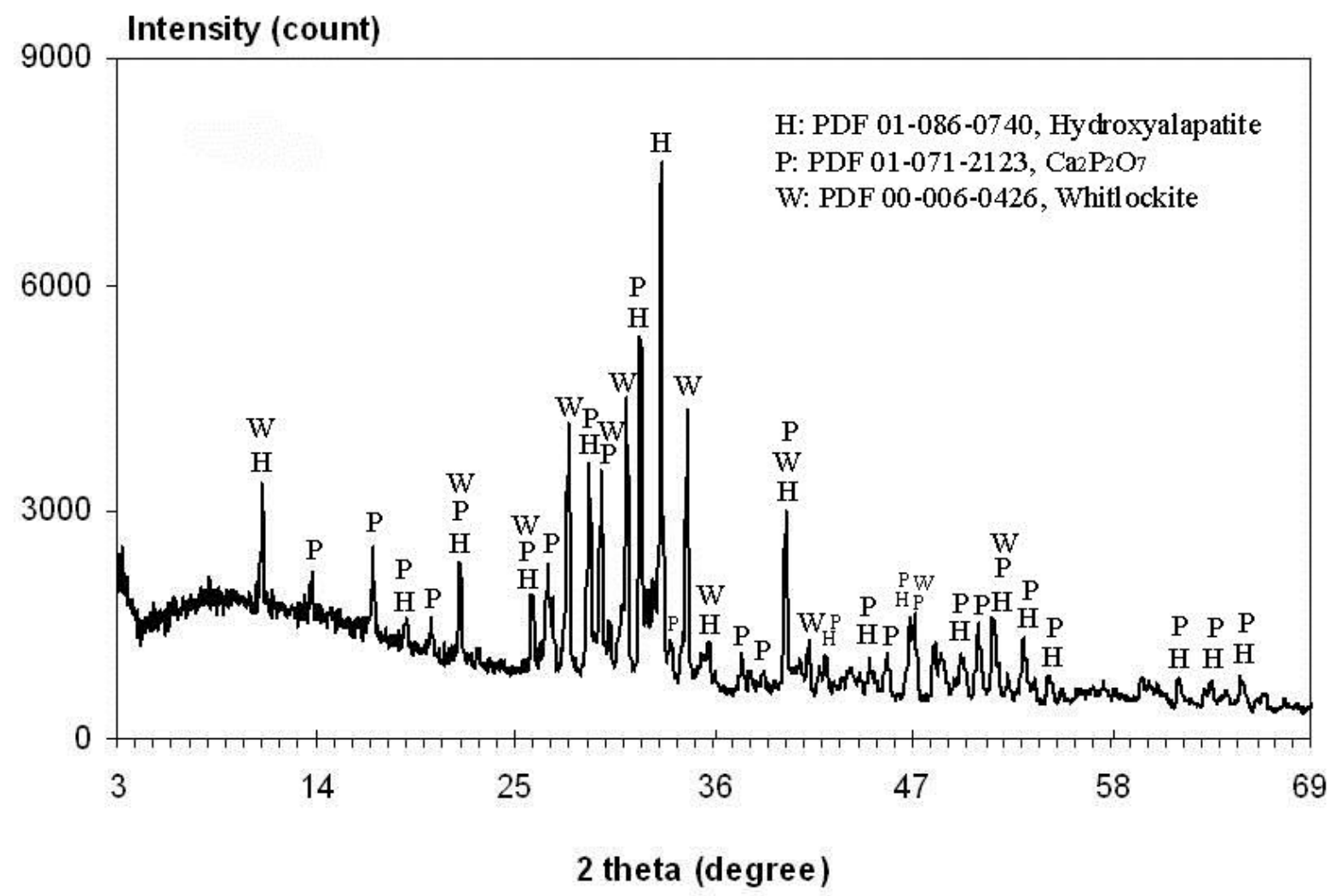

Fig. 7. XRD pattern of sample W4 after heat treatment at $800^{\circ} \mathrm{C}$ for $2 \mathrm{~h}$. 


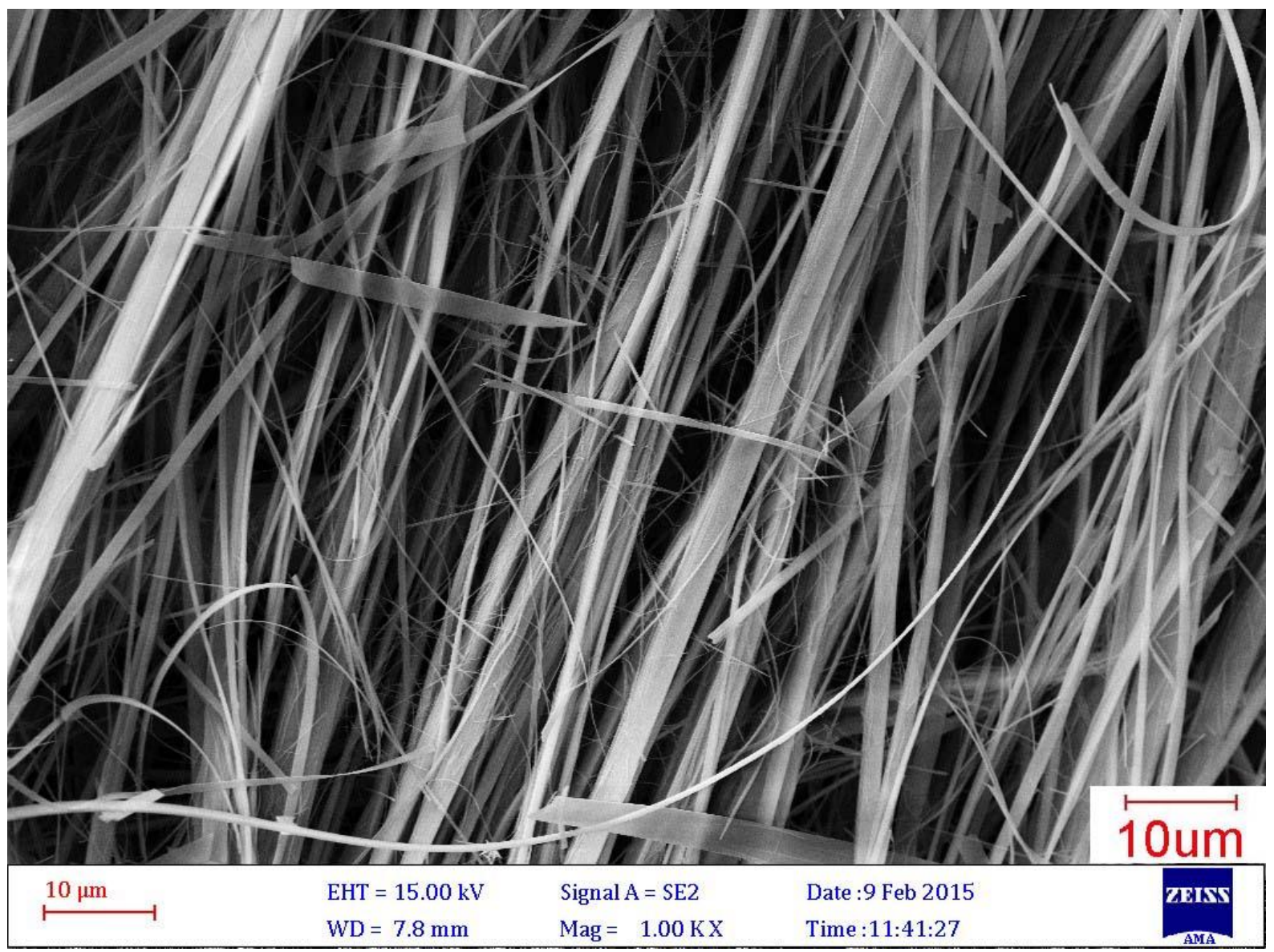

Fig. 8. FE-SEM image of heat-treated W4 fibers. 


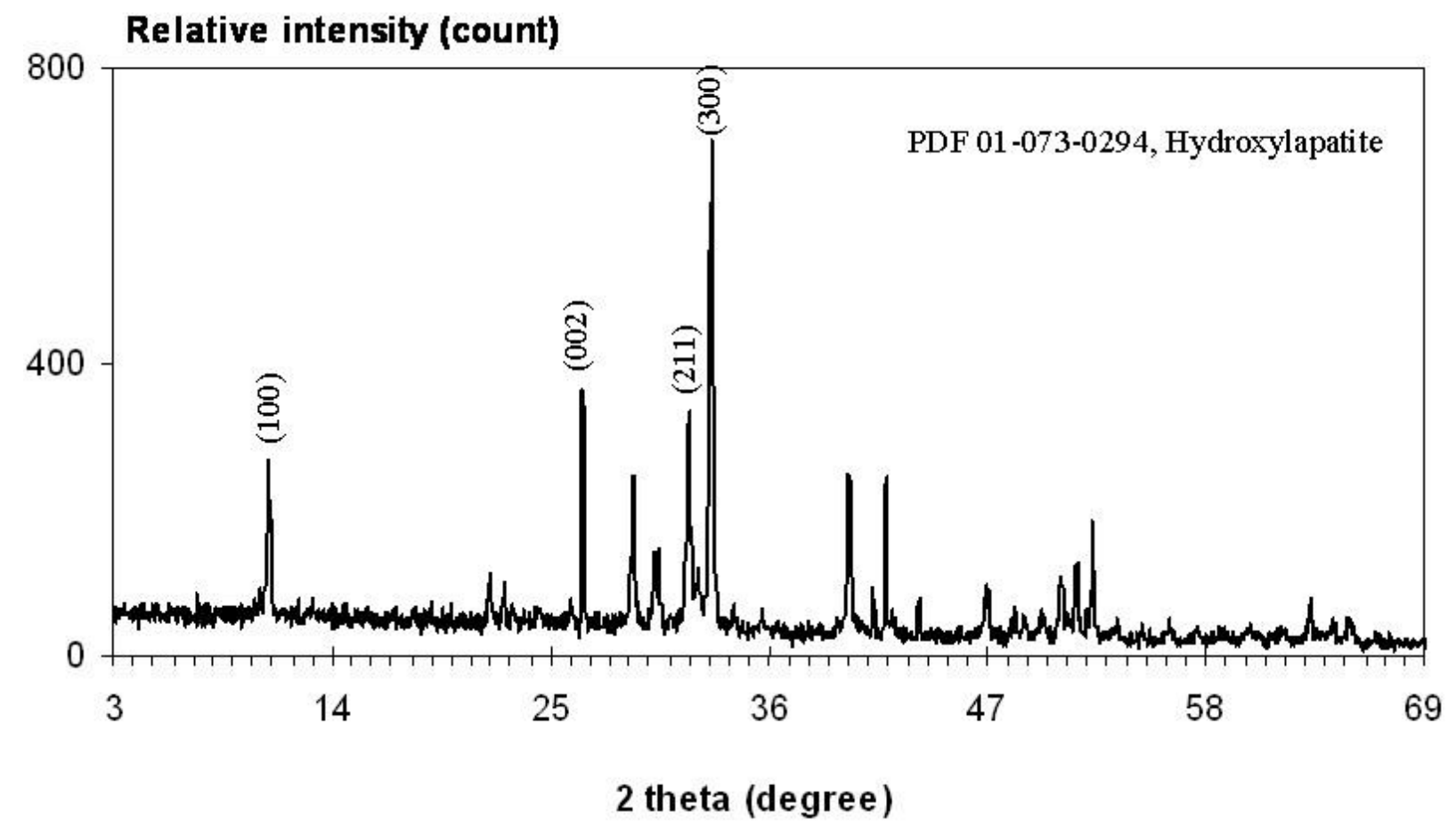

Fig. 9. XRD pattern of whisker W8. 
Table 1

Synthesis parameters (all at $90^{\circ} \mathrm{C}$, starting solution of $\mathrm{pH} 3.0$ and $\mathrm{Ca} / \mathrm{P}$ molar ratio of 1.67).

\begin{tabular}{cccr}
\hline Time (days) & Urea/[Ca] $(\mathrm{mM} / \mathrm{mM})$ & {$[\mathrm{Ca}](\mathrm{mM})$} & Precipitate \\
\hline 3 & 0 & 100 & W1 \\
3 & 0.1 & 100 & W2 \\
3 & 0.2 & 100 & W3 \\
3 & 0.4 & 100 & W4 \\
6 & 5.0 & 100 & W5 \\
10 & 5.0 & 100 & W6 \\
10 & 5.0 & 100 & W7 \\
\hline
\end{tabular}


Table 2

$\mathrm{Ca} / \mathrm{P}$ molar ratio, carbonate content, and peak intensity ratio of hydroxyapatite whiskers determined by ICP, elemental analyzer, and XRD, respectively.

\begin{tabular}{rrrrr}
\hline $\mathrm{I}_{300} / \mathrm{I}_{210}(\mathrm{ref})$ & $\mathrm{I}_{300} / \mathrm{I}_{002}(\mathrm{ref})$ & $\mathrm{CO}_{3}{ }^{2-}$ (wt\%) & $\mathrm{Ca} / \mathrm{P}$ (molar ratio) & Precipitate \\
\hline $5.0(3.9)$ & $6.9(1.3)$ & 6.8 & 1.65 & Whisker W7 \\
$3.2(3.8)$ & $4.8(1.7)$ & 0.8 & 1.63 & Whisker W8 \\
\hline
\end{tabular}

